\title{
Frailty and risk in proximal aortic surgery
}

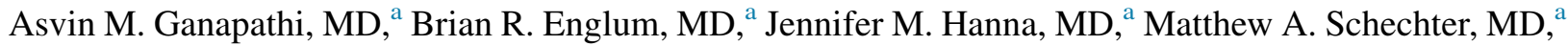 \\ Jeffrey G. Gaca, MD, ${ }^{a}$ Lynne M. Hurwitz, MD, ${ }^{b}$ and G. Chad Hughes, MD ${ }^{a}$
}

\begin{abstract}
Objectives: Although frailty has recently been examined in various populations as a predictor of morbidity and mortality, its effect on thoracic aortic surgery outcomes has not been studied. The objective of the present study was to evaluate the role of frailty in predicting postoperative morbidity and mortality in patients undergoing proximal aortic replacement surgery.
\end{abstract}

\begin{abstract}
Methods: A retrospective analysis of a prospectively maintained database was performed for all patients undergoing elective and nonelective proximal aortic operations (root, ascending aorta, and/or arch) at a singlereferral institution from June 2005 to December 2012. A total of 581 patients underwent proximal aortic surgery, of whom $574(98.8 \%)$ were included in the present analysis; 7 were excluded because of incomplete data. Frailty was evaluated using an index consisting of age $>70$ years, body mass index $<18.5 \mathrm{~kg} / \mathrm{m}^{2}$, anemia, history of stroke, hypoalbuminemia, and total psoas volume in the bottom quartile of the population. One point was given for each criterion met to determine a frailty score of 0 to 6 . Frailty was defined as a score of $\geq 2$. Risk models for length of stay $>14$ days, discharge to other than home, 30-day composite major morbidity, 30-day composite major morbidity/mortality, and 30-day and 1-year mortality were calculated using multivariate regression modeling.

Results: Of the 574 patients, $148(25.7 \%)$ were defined as frail (frailty score $\geq 2$ ). The unadjusted 30-day/in-hospital and long-term outcomes were significantly worse for the frail versus nonfrail patients in all but 1 of the outcomes analyzed; no difference was found in the 30-day readmission rates between the 2 groups. In the multivariate model, a frailty score of $\geq 2$ was associated with discharge to other than home and 30-day and 1-year mortality.
\end{abstract}

Conclusions: Frailty, as defined using a 6-component frailty index, can serve as an independent predictor of discharge disposition and early and late mortality risk in patients undergoing proximal aortic surgery. These frailty markers, all of which are easily assessed preoperatively, could provide valuable information for patient counseling and risk stratification before proximal aortic replacement. (J Thorac Cardiovasc Surg 2014;147:186-91)

Supplemental material is available online.

Repairs of the ascending thoracic aorta and arch have been demonstrated to carry significant potential morbidity and mortality risk. $^{1,2}$ A recent study from The Society of Thoracic Surgeons (STS) Adult Cardiac Surgery Database examining outcomes in 45,894 patients undergoing ascending aorta replacement (with or without root), with or without arch replacement, from 2004 to 2009 found

From the Division of Cardiovascular and Thoracic Surgery, ${ }^{\mathrm{a}}$ Department of Surgery, and Department of Radiology, ${ }^{\mathrm{b}}$ Duke University Medical Center, Durham, NC.

Disclosures: G. Chad Hughes reports consulting fees from W.L. Gore and Associates and Medtronic Vascular. The other authors have nothing to disclose with regard to commercial support.

Read at the 39th Annual Meeting of The Western Thoracic Surgical Association, Coeur d'Alene, Idaho, June 26-29, 2013.

Received for publication June 26, 2013; revisions received Aug 20, 2013; accepted for publication Sept 4, 2013; available ahead of print Nov 1, 2013.

Address for reprints: G. Chad Hughes, MD, Director, Aortic Surgery Program, Division of Cardiovascular and Thoracic Surgery, Duke University Medical Center, Box 3051, Durham, NC 27710 (E-mail: gchad.hughes@duke.edu).

$0022-5223 / \$ 36.00$

Copyright (c) 2014 by The American Association for Thoracic Surgery

http://dx.doi.org/10.1016/j.jtcvs.2013.09.011 nonelective case status to be the strongest predictor of major morbidity or mortality, although other comorbid conditions such as severe chronic lung disease, chronic kidney disease, and cerebrovascular disease also predicted an increased risk. ${ }^{2}$ Frailty, defined as a state of increased vulnerability to stressors caused by deterioration across multiple physiologic systems, is an independent risk factor for in-hospital mortality, reduced midterm survival, and prolonged residential care requirements in cardiac surgery. ${ }^{3}$ Frailty was not examined in the aforementioned large STS Adult Cardiac Surgery Database study, and no other work to date has attempted to examine the effect of frailty on thoracic aortic surgery outcomes. Therefore, the present study sought to establish an objective frailty score for patients undergoing proximal aortic surgery and to evaluate its independent predictive value relative to known risk factors to further improve on existing risk stratification models.

\section{METHODS}

\section{Patients and Data Source}

A retrospective analysis of a prospectively maintained database was performed for all patients undergoing elective and nonelective proximal aortic operations at a single tertiary referral institution from June 2005 


\author{
Abbreviations and Acronyms \\ $\mathrm{FP}=$ frail patient \\ $\mathrm{NFP}=$ nonfrail patient \\ STS $=$ The Society of Thoracic Surgeons \\ $\mathrm{TPV}=$ total psoas volume
}

to December 2012. Proximal aortic surgery was defined as any procedure involving the aortic root, ascending aorta, and/or aortic arch, performed through a median sternotomy, and using cardiopulmonary bypass with or without hypothermic circulatory arrest. Operations classified as hybrid arch procedures or involving the descending thoracic aorta were excluded. The pre-, intra-, and postoperative variables were obtained from the Duke Thoracic Aortic Surgery Database, a prospectively maintained clinical registry of all patients undergoing thoracic aortic surgery at Duke University Medical Center (Durham, NC). The need for individual patient consent was waived after review and approval by the institutional review board of Duke University. A query of the database identified 581 proximal aortic procedures performed from June 2005 to December 2012. Of these, $574(98.8 \%)$ were included in the present analysis; 7 patients were excluded because of incomplete data. The comorbidities and patient characteristics were defined using STS definitions. ${ }^{4}$ All patients underwent annual follow-up examinations at the Duke University Center for Aortic Disease with clinical assessment and computed tomographic angiography, magnetic resonance angiography, and/or echocardiography. Data were collected through the last follow-up visit by the study termination date of December 2012. In addition, the Social Security Death Index (available at: http://ssdi. rootsweb.com/) was queried to confirm all deaths and survey for patients lost to follow-up.

\section{Frailty Definition}

To classify frailty, a score consisting of 6 components previously identified in the published data as objective indicators of frailty was created. The components were (1) age $>70$ years, ${ }^{5}$ (2) body mass index $<18.5 \mathrm{~kg} / \mathrm{m}^{2},{ }^{6}(3)$ anemia $(<12.0 \mathrm{~g} / \mathrm{dL}$ for women, $<13.0 \mathrm{~g} / \mathrm{dL}$ for men), ${ }^{7}$ (4) hypoalbuminemia $(<3.5 \mathrm{~g} / \mathrm{dL}),{ }^{8}(5)$ a history of stroke, ${ }^{9}$ and (6) a total psoas volume (TPV) in the bottom quartile of the patient population. ${ }^{10}$ For each characteristic a patient fulfilled, they received 1 point to establish a score from 0 to 6 . Any patient with a score of $\geq 2$ was defined as frail, analogous to previously published definitions. ${ }^{5,9}$ Any missing value among the components of the frailty score was considered normal.

TPV measurements were made using a TeraRecon Aquarius 3-dimensional workstation (TeraRecon Inc, San Mateo, Calif) for all patients with computed tomography scans of the abdomen and pelvis extending to the acetabulum $(n=265 ; 46.1 \%)$. To perform the TPV measurements, the region of interest tool was used to outline the psoas muscle bilaterally on axial images (Figure E1). The selection of the psoas muscle began at the L1 level and continued through the acetabulum, with measurements made at each vertebral level and at approximately 3 equidistant measurements between the top of the sacrum and the acetabulum (total of 8 measurements). Once the psoas muscle had been outlined at the 8 predetermined locations, the volume tool was used to determine the TPV. To account for the potential inclusion of fat or other tissue within the psoas volume, density thresholds of 0 to 161 Hounsfield units, consistent with previous data, ${ }^{10}$ were used to select muscle and exclude fat, vasculature, and bone. The resultant TPV was then calculated. Three independent observers, who were unaware of the patient's clinical information, performed the TPV measurements, with multiple measurements made for randomly assigned scans (one third of all measurements) to validate interobserver reliability.

\section{Outcomes}

The primary outcome measure was mortality, both 30 day and 1 year. The secondary outcomes included length of stay $>14$ days, discharge to a destination other than home, readmission within 30 days, composite 30-day major morbidity, and composite 30-day major morbidity and mortality. The composite 30-day major morbidity was defined using the standard STS definition and included reoperation, prolonged mechanical ventilation, acute renal failure, new onset dialysis, and stroke.

\section{Statistical Analysis}

Categorical variables were compared using the chi-square test and continuous variables using Student's $t$ test. Backward, stepwise, multivariate logistic regression modeling was used to determine the independent effect of frailty on these outcomes, while controlling for known risk factors. A Kaplan-Meier survival analysis with the log-rank test was used for the long-term survival estimates. The significance levels were set at an $\alpha$ of 0.05 in all cases. We made an affirmative decision to control for a type I error at the level of the comparison; therefore, no corrections for multiple hypothesis testing were made. Statistical analysis was performed using R, version 2.15.1 (Vienna, Austria).

\section{RESULTS}

The study cohort consisted of 574 total procedures in 569 patients. Of these patients, $148(25.7 \%)$ were defined as frail (frailty score $\geq 2$ ). The frail patients (FPs) were older and more likely to be women. They also had a greater comorbid disease burden, including a more frequent history of previous stroke and/or transient ischemic attack, chronic obstructive pulmonary disease, and chronic renal insufficiency, and were more likely to be American Society of Anesthesiologists class 4 (Table 1). The patients in the frail and nonfrail groups did not differ in the type of proximal aortic procedure performed or the incidence of redo sternotomy (Table 2). However, the FPs were more likely to undergo nonelective (urgent and emergent) surgery, including more frequent surgery for aortic dissection, and were also significantly more likely to require concomitant cardiac surgical procedures, most of which were coronary artery bypass grafting $(76 \%)$.

Examination of the individual frailty characteristics revealed that 280 of the $426(65.7 \%)$ nonfrail patients (NFPs) did not meet any of the frailty criteria. Of the NFPs fulfilling only 1 frailty criterion, the most common finding was the presence of anemia $(n=60 ; 14.1 \%)$. In contrast, anemia $(\mathrm{n}=112 ; 75.7 \%)$ and hypoalbuminemia $(\mathrm{n}=104 ; 70.3 \%)$ were the most common characteristics present in the FPs (Table E1). Nearly all FPs had a frailty score of 2 or $3(n=140 ; 94.6 \%)$, with no patient having a score of 6 (Table E2). Fewer than one half of the FPs $(\mathrm{n}=66 ; 44.6 \%)$ were elderly, defined as age $>70$ years. The unadjusted perioperative (30-day and in-hospital) and long-term outcomes revealed significant differences between the FPs and NFPs in all but 1 of the outcomes analyzed (Table 3 ). The single exception was the absence of a difference in the 30-day readmission rates between the 2 groups. Mortality at 30 days and 1 year for the entire 
TABLE 1. Preoperative patient characteristics

\begin{tabular}{|c|c|c|c|c|}
\hline Variable & $\begin{array}{c}\text { Overall } \\
(n=574)\end{array}$ & $\begin{array}{c}\text { Frail } \\
(n=148)\end{array}$ & $\begin{array}{l}\text { Not frail } \\
(n=426)\end{array}$ & $\begin{array}{c}P \\
\text { value }\end{array}$ \\
\hline \multicolumn{5}{|l|}{ Demographics } \\
\hline Age (y) & $56.1 \pm 14.4$ & $63.4 \pm 14.7$ & $53.5 \pm 13.4$ & $<.01 *$ \\
\hline Male gender & $404(70.3)$ & $80(54.1)$ & $324(76.1)$ & $<.01 *$ \\
\hline White race & $430(74.9)$ & $86(58.1)$ & $344(80.7)$ & $<.01 *$ \\
\hline BMI $\left(\mathrm{kg} / \mathrm{m}^{2}\right)$ & $28.5 \pm 6.2$ & $27.8 \pm 6.9$ & $28.7 \pm 5.9$ & .13 \\
\hline \multicolumn{5}{|l|}{ Comorbidities } \\
\hline Hypertension & $448(78.0)$ & $127(85.8)$ & $321(75.4)$ & $<.01 *$ \\
\hline Hyperlipidemia & $288(50.1)$ & $85(57.4)$ & 203 (47.7) & $<.01 *$ \\
\hline History of tobacco use & $265(46.2)$ & $76(51.4)$ & $189(44.4)$ & .14 \\
\hline Diabetes & $49(8.5)$ & $17(11.5)$ & $32(7.5)$ & .14 \\
\hline Coronary artery disease & $131(22.8)$ & $55(37.2)$ & $76(17.8)$ & $<.01 *$ \\
\hline History of stroke or TIA & $40(7.0)$ & $25(16.9)$ & $15(3.5)$ & $<.01 *$ \\
\hline COPD & $72(12.5)$ & $36(24.3)$ & $36(8.5)$ & $<.01 *$ \\
\hline $\begin{array}{l}\text { Baseline creatinine } \\
>1.5 \mathrm{mg} / \mathrm{dL}\end{array}$ & $64(11.2)$ & $32(21.6)$ & $32(7.5)$ & $<.01^{*}$ \\
\hline $\begin{array}{l}\text { Peripheral vascular } \\
\text { disease }\end{array}$ & $30(5.2)$ & $12(8.1)$ & $18(4.2)$ & .07 \\
\hline \multicolumn{5}{|l|}{ Baseline laboratory values } \\
\hline Hemoglobin (g/dL) & $13.2 \pm 2.0$ & $11.2 \pm 1.8$ & $13.9 \pm 1.5$ & $<.01 *$ \\
\hline Albumin $(\mathrm{g} / \mathrm{dL}) \dagger$ & $3.7 \pm 0.5$ & $3.2 \pm 0.5$ & $3.9 \pm 0.3$ & $<.01 *$ \\
\hline \multicolumn{5}{|l|}{ Operative information } \\
\hline Ejection fraction & $52.6 \pm 6.2$ & $52.3 \pm 6.8$ & $52.7 \pm 6.1$ & .58 \\
\hline ASA class 4 & $182(31.7)$ & 72 (48.6) & $110(25.8)$ & $<.01^{*}$ \\
\hline Maximal aortic diameter & $5.6 \pm 1.1$ & $5.7 \pm 1.5$ & $5.6 \pm 1.0$ & .35 \\
\hline
\end{tabular}

cohort was 3.3\% $(\mathrm{n}=19)$ and $7.8 \%(\mathrm{n}=38)$, respectively, but only $1.4 \%$ and $4.2 \%$ for the nonfrail group. Mortality was significantly increased in the frail cohort at $8.8 \%$ and $18.1 \%$ at 30 days and 1 year, respectively.

Using multivariate logistic regression modeling, frailty was independently associated with discharge to a

TABLE 2. Operative characteristics

\begin{tabular}{|c|c|c|c|c|}
\hline Variable & $\begin{array}{c}\text { Overall } \\
(n=574)\end{array}$ & $\begin{array}{c}\text { Frail } \\
(n=148)\end{array}$ & $\begin{array}{l}\text { Not frail } \\
(n=426)\end{array}$ & $\begin{array}{c}P \\
\text { value }\end{array}$ \\
\hline \multicolumn{5}{|l|}{ Indication } \\
\hline Dissection & $145(25.3)$ & $64(43.2)$ & $81(19.0)$ & $<.01 *$ \\
\hline \multicolumn{5}{|l|}{ Procedure performed } \\
\hline RR/ASC only & $113(19.7)$ & $26(17.6)$ & $87(20.4)$ & .45 \\
\hline RR/ASC with hemiarch & $419(73.0)$ & $107(72.3)$ & $312(73.2)$ & .82 \\
\hline RR/ASC with total arch & $42(73.2)$ & $15(10.1)$ & $27(6.3)$ & .13 \\
\hline Redo sternotomy & $139(24.2)$ & $38(25.7)$ & $101(23.7)$ & .63 \\
\hline $\begin{array}{l}\text { Concomitant cardiac } \\
\text { surgical procedure }\end{array}$ & $137(23.7)$ & $50(33.8)$ & $87(20.4)$ & $<.01 *$ \\
\hline \multicolumn{5}{|l|}{ Case status } \\
\hline Elective & $425(74.0)$ & $83(56.1)$ & $342(80.3)$ & $<.01 *$ \\
\hline Urgent & $71(12.4)$ & $34(23.0)$ & $37(8.7)$ & $<.01 *$ \\
\hline Emergent & $78(13.6)$ & $31(20.9)$ & $47(11.0)$ & $<.01 *$ \\
\hline
\end{tabular}

Data presented as $\mathrm{n}(\%) . R R / A S C$, Root replacement or ascending aorta. *Statistically significant.
TABLE 3. Unadjusted perioperative and long-term outcomes

\begin{tabular}{|c|c|c|c|c|}
\hline Outcome & $\begin{array}{c}\text { Overall } \\
(\mathrm{n}=574)\end{array}$ & $\begin{array}{c}\text { Frail } \\
(n=148)\end{array}$ & $\begin{array}{l}\text { Not frail } \\
(\mathrm{n}=426)\end{array}$ & $\begin{array}{c}P \\
\text { Value } \\
\end{array}$ \\
\hline Length of stay $>14 d$ & $47(8.2)$ & $23(15.5)$ & $24(5.6)$ & $<.01 *$ \\
\hline $\begin{array}{l}\text { Discharge to location } \\
\text { other than home }\end{array}$ & $39(6.7)$ & $25(16.9)$ & $14(3.2)$ & $<.01 *$ \\
\hline $\begin{array}{l}\text { Readmission within } \\
30 \mathrm{~d}\end{array}$ & $54(9.4)$ & $15(10.1)$ & $39(9.2)$ & .72 \\
\hline $\begin{array}{l}\text { Composite } 30-\mathrm{d} \\
\text { major morbidity }\end{array}$ & $111(19.3)$ & $42(28.4)$ & $69(16.2)$ & $<.01 *$ \\
\hline $\begin{array}{l}\text { Composite } 30-\mathrm{d} \text { major } \\
\text { morbidity and } \\
\text { mortality }\end{array}$ & $120(20.9)$ & $47(31.8)$ & $73(17.1)$ & $<.01 *$ \\
\hline 30-d Mortality & $19(3.3)$ & $13(8.8)$ & $6(1.4)$ & $<.01 *$ \\
\hline 1-y Mortality $\dagger$ & $38 / 482(7.8)$ & 23/127 (18.1) & $15 / 355(4.2)$ & $<.01 *$ \\
\hline
\end{tabular}

destination other than home and 30-day and 1-year mortality, with risk-adjusted odds ratios of 3.7 (95\% confidence interval, 1.8-7.7; $P<.01), 5.0$ (95\% confidence interval, $2.4-9.7 ; P<.01)$, and 4.5 (95\% confidence interval 2.1-9.6; $P<.01$ ), respectively (Table 4). Total arch replacement was significantly associated with all outcomes examined, except for the 30-day readmission rate. None of the variables, including frailty, were retained after attempting to create a backward, stepwise, multivariate logistic regression model for 30-day readmission (all variables removed from model using $P>.2$, as determined a priori). Consequently, no statistically significant model for 30-day readmission was created. Late survival, assessed using Kaplan-Meier analysis with the log-rank test, revealed significantly worse long-term survival among the frail cohort (Figure 1).

\section{DISCUSSION}

Although risk models have recently been developed for 30-day and in-hospital major morbidity and mortality in proximal thoracic aortic surgery, ${ }^{2}$ no study has examined the effect of frailty in this population, for either short- or long-term outcomes. The present study has presented a novel frailty scoring system that uses easily assessed, objective preoperative variables that can quickly assess an individual patient's frailty status. Defined by a score of $\geq 2$, frailty was independently associated with discharge to a destination other than home and 30-day and 1-year mortality. Consistent with the existing data, the FPs were older and had a greater comorbid disease burden. ${ }^{5,11-13}$ Fewer than one half were elderly, suggesting age alone is an insufficient marker of this state of physiologic deterioration. The present study was also unique in presenting risk models for 1-year mortality, information that could be useful to clinicians when counseling patients and their families.

Given the increasing age of patients undergoing cardiac surgery ${ }^{14,15}$ and the significant potential for morbidity and 
TABLE 4. Multivariate predictors of outcome in proximal aortic replacement

\begin{tabular}{|c|c|c|c|c|c|c|}
\hline Variable & LOS $>14 d$ & $\begin{array}{c}\text { Discharge to } \\
\text { destination other } \\
\text { than home } \\
\end{array}$ & $\begin{array}{c}\text { Composite 30-d } \\
\text { morbidity } \\
\end{array}$ & $\begin{array}{c}\text { Composite 30-d } \\
\text { morbidity and } \\
\text { mortality } \\
\end{array}$ & 30-d mortality & 1-y mortality \\
\hline Frail status & NS & $3.7(1.8-7.7 ;<.01)$ & NS & NS & $5.0(1.8-14.0 ;<.01)$ & $4.5(2.1-9.6 ;<.01)$ \\
\hline ASA class 4 & NS & $2.7(1.3-5.7 ;<.01)$ & NS & NS & NS & NS \\
\hline $\mathrm{CCP}$ & $5.0(2.5-9.9 ;<.01)$ & NS & $3.7(2.3-5.9 ;<.01)$ & $3.5(2.2-5.6 ;<.01)$ & NS & NS \\
\hline Female gender & $2.2(1.1-4.5 ; .03)$ & NS & NS & NS & NS & NS \\
\hline Nonelective status & $4.2(2.1-8.8 ;<.01)$ & NS & $3.6(2.3-5.7 ;<.01)$ & $3.6(2.3-5.7 ;<.01)$ & NS & NS \\
\hline PVD & NS & $3.5(1.2-10.4 ; .02)$ & NS & NS & NS & NS \\
\hline $\begin{array}{l}\text { Presence of aortic } \\
\text { dissection }\end{array}$ & NS & NS & NS & NS & $3.1(1.2-8.5 ; .03)$ & $2.3(1.1-4.7 ; .03)$ \\
\hline Renal insufficiency & $3.3(1.5-7.1 ;<.01)$ & $3.8(1.8-8.3 ;<.01)$ & NS & NS & NS & NS \\
\hline Total arch replacement & $10.8(4.4-26.6 ;<.01)$ & $3.0(1.2-8.0 ; .02)$ & $3.7(1.8-7.7 ;<.01)$ & $4.8(2.4-9.7 ;<.01)$ & $4.9(1.7-14.6 ;<.01)$ & $7.7(3.3-18.1 ;<.01)$ \\
\hline
\end{tabular}

Data presented as odds ratio ( $95 \%$ confidence interval; $P$ value). $L O S$, Length of stay; $N S$, nonsignificant; $A S A$, American Society of Anesthesiologists; $C C P$, concomitant cardiac surgical procedure; $P V D$, peripheral vascular disease.

mortality in proximal thoracic aortic surgery, especially in the nonelective setting, ${ }^{2}$ a better understanding of all potential risk factors for these procedures is necessary. The current risk models, such as the STS Risk Calculator, EuroSCORE, and Ambler score, attempt to provide estimates of postoperative mortality risk; however, concerns exist regarding their utility for high-risk patients and the lack of data on long-term mortality. ${ }^{16-21}$ The STS Risk Calculator and Ambler score do not provide risk stratification for isolated proximal aortic surgery, and it has been suggested that they do not appropriately assess elderly patients, because they do not account for physiologic reserve. ${ }^{3}$ Thus, frailty is believed to provide the missing element to appropriately determine the operative risks in this population.

Originally used to describe elderly medical patients in the community, ${ }^{12,22,23}$ the concept of frailty has recently been

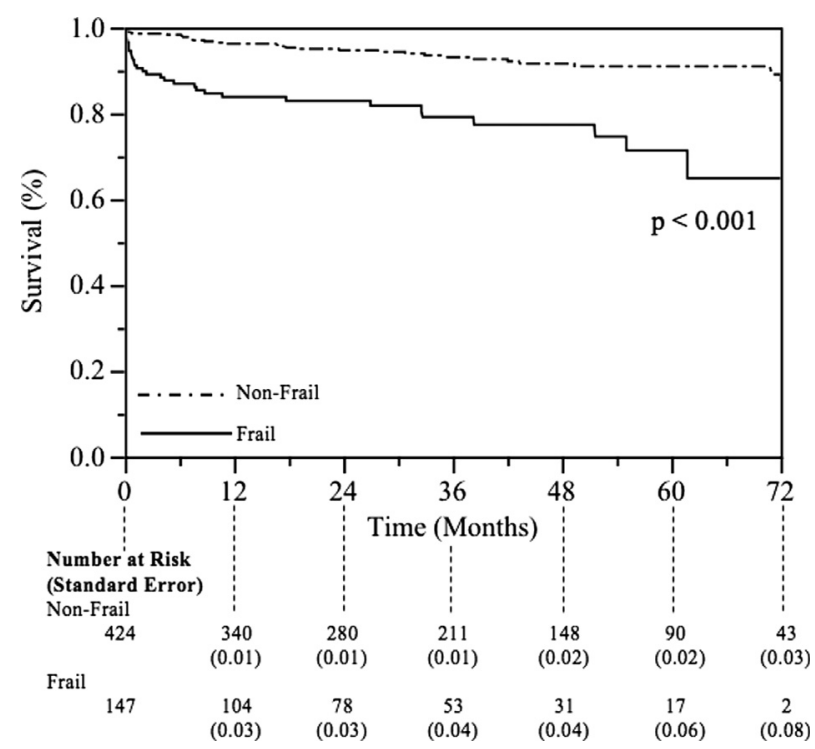

FIGURE 1. Unadjusted Kaplan-Meier survival curves for frail and nonfrail patients. studied in various surgical populations. ${ }^{9,11,24}$ However, many of the current methods used to determine frailty rely on subjective assessments or require significant effort to conduct all the necessary evaluations. ${ }^{25-28}$ Lee and colleagues $^{5}$ reported the first study of frailty in cardiac surgery patients. They examined its effect on elective cardiac surgery outcomes. ${ }^{5}$ Defined as the presence of impairment of activities of daily living, ambulation, or dementia, they reported worse outcomes for patients classified as frail..$^{5}$ Sünderman and colleagues ${ }^{13}$ presented a more comprehensive measure of frailty in elderly patients, including objective data, such as laboratory values, pulmonary function tests, and grip strength, and subjective assessments of self-reported exhaustion and physical activity scores. Similarly, a poor prognosis of the FPs relative to the NFPs was noted in their study. However, their assessment was dependent on extensive observation of the patients, which might not be feasible at all institutions or in nonelective clinical settings. They also relied on subjective data that could vary among patients. ${ }^{13}$ Recently, the advent of transcatheter aortic valve replacement, which has been proposed as an alternative treatment option for aortic stenosis in high-risk and inoperable patients, has spurred others to assess the role of frailty in valve replacement. $^{3,29,30}$ One metric frequently used in transcatheter aortic valve replacement assessment has been the 6-minute walk test, which has been found to provide additive prognostic value to the EuroSCORE, although the utility of this test has also been limited because it is not generally obtainable in the nonelective setting. ${ }^{31}$

Unlike previous work, the definition of frailty presented in the present study allows for the efficient identification of FPs using only easily obtained, objective preoperative data. All 6 of the characteristics used to calculate the frailty score have been previously described as markers of frailty in the published data. ${ }^{6,7,9,32}$ Anemia, hypoalbuminemia, and a low body mass index can have negative effects on the physiologic reserve and were important for inclusion. 
Previous stroke was included as a part of the definition, because this can lead to impaired ability to perform activities of daily living, ambulate, or function independently. The use of TPV in the lowest quartile of the measurements as the last criteria in the scoring system stemmed from recent data describing a total psoas area at a specified vertebral level as a surrogate for frailty that has been associated with reduced survival in surgical patients. ${ }^{10,32,33}$ Because no definitive numerical values exist for which total psoas area would indicate a FP, we believed it appropriate to use the TPV instead. Measurement of the TPV accounts for the entire muscle, eliminating the potential sampling error of quantifying the area at 1 vertebral level. Additionally, TPV measurements can be made easily using the methods we have described. Previous studies defined the lowest quartile of TPV in the studied population to be an appropriate frailty marker, and we used the same convention. ${ }^{10}$ To address the potential of nonreproducibility of measurements, an interobserver intraclass correlation coefficient of 0.98 was calculated among the measurements from 3 independent observers, strongly suggesting the reliability of the independent measurements. Finally, measurement of the TPV takes approximately 5 minutes to complete, reinforcing its ease of use. However, should one not have access to a 3-dimensional workstation, required to calculate the TPV, repeat analysis of the data, removing the TPV from the frailty score, led to 17 patients originally classified as frail to be reclassified as nonfrail. Although the overall results of the multivariate model did not change, with frailty remaining an independent risk factor for discharge to a destination other than home and 30-day and 1-year mortality, a small, but noticeable, decrease occurred in the strength of the statistical significance of the frailty variable (data not shown). Therefore, these results suggest that, if unavailable, frailty can be classified without the TPV, although a more accurate prediction of outcomes will be seen with inclusion of TPV in the frailty determination.

One important aspect of the novel frailty definition proposed in the present study is its applicability to all age groups. Historically, frailty has been used to describe only elderly patients, usually those aged $>65$ years. However, the disease processes that contribute to proximal thoracic aortic pathology often affect younger patients and may also contribute to a diminished physiologic reserve. Therefore, the inclusion of multiple factors to assess frailty in younger patients was thought to be important. Consistent with this supposition, fewer than one half of the FPs in the present study were aged $>70$ years.

Another important point to consider is the association of frailty with 1-year mortality. Previous risk models and definitions of frailty have focused on the short-term outcomes and thus have failed to capture any deaths occurring beyond the 30-day and/or in-hospital perioperative window. The lack of data in that period is less than ideal, because patients not fulfilling traditional risk factors, but with diminished physiologic reserve, could be particularly susceptible to major morbidity and/or mortality beyond 30 days. Additionally, it has been suggested that some assessment of frailty might be important when considering the benefit of a procedure for a given patient, particularly in the elderly. ${ }^{28}$ Thus, classifying patients as frail has the potential to offer surgeons another tool to risk stratify operative candidates and provide appropriate preoperative counseling, because patients experiencing 1-year mortality generally do not obtain a meaningful survival benefit from their procedure. ${ }^{34}$

Also warranting discussion is the incidence of frailty and the distribution of frailty scores within the study cohort. Nearly one half the patients $(48.7 \%)$ did not meet any of the specified criteria, and $74.2 \%$ of patients were considered not frail. Estimates of frailty in community middle-age (aged 50-64 years) and elderly patients (aged $\geq 65$ years) have ranged from $1 \%$ to $8 \%$ and $6 \%$ to $27 \%$, respectively. ${ }^{35}$ The incidence of frailty in cardiac surgery patients has ranged from $4 \%$ to $50 \%{ }^{5,13}$ The proportion of FPs $(25.7 \%)$ in the present study was within these ranges. It should be noted that differences in the number of FPs between studies were likely secondary to alternative definitions and disparate patient populations. In the present study, almost all FPs fulfilled only 2 or 3 criteria, with just 8 FPs $(5.4 \%)$ having a frailty score of $\geq 4$, and none having a score of 6 . This distribution of frailty scores might represent patient selection at our institution. Although it would have been desirable to examine the effect of an increasing frailty score on morbidity and mortality, the distribution of these scores, and the low event rate in the study, precluded any meaningful statistical analysis of a progressively elevated frailty score. Finally, no difference was found in the 30-day readmission rate between the FP and NFPs. This observation can be explained by the increased likelihood of FPs being discharged to skilled nursing facilities and having a longer length of stay and, thus, minimizing their 30-day readmission rate.

\section{Study Limitations}

The present study had a number of important limitations. First, the study was a single-institution, retrospective study and, consequently, was subject to various forms of bias. Additionally, we had 394 missing values (11.1\%; 85 missing albumin values and 309 missing psoas values), which were assumed to be normal. This assumption could have underestimated the number of FPs and, ultimately, affected the presented results. Finally, given the single-institution nature of the study, the outcomes presented might not be generalizable to other centers. 


\section{CONCLUSIONS}

The concept of frailty is becoming an increasingly important topic to consider in the current era of cardiac surgery, because, given the aging of the population, the number of elderly and infirm patients referred for possible surgical management of their aortic disease has continued to increase. A better understanding of this previously subjective term will help guide patient selection and allow surgeons to provide objective risk stratification using the easily calculated frailty definition we have presented. We have demonstrated that classification of frailty, as defined by the presence of any 2 of 6 preoperative characteristics, including age $>70$ years, low body mass index, anemia, hypoalbuminemia, a history of stroke, and low TPV, is independently associated with discharge to a destination other than home and poorer 30-day and/or in-hospital and 1-year survival after proximal aortic replacement surgery. Furthermore, this frailty risk is independent of that predicted using traditional risk factors.

\section{References}

1. Krahenbuhl ES, Immer FF, Stalder M, Englberger L, Eckstein FS, Schmidli J, et al. Technical advances improved outcome in patients undergoing surgery of the ascending aorta and/or aortic arch: ten years' experience. Eur J Cardiothorac Surg. 2008;34:595-9.

2. Williams JB, Peterson ED, Zhao Y, O'Brien SM, Andersen ND, Miller DC, et al. Contemporary results for proximal aortic replacement in North America. J Am Coll Cardiol. 2012;60:1156-62.

3. Chikwe J, Adams DH. Frailty: the missing element in predicting operative mortality. Semin Thorac Cardiovasc Surg. 2010;22:109-10.

4. Adult Cardiac Surgery Database Training Manual version 2.73, 2012. Available at: http://www.sts.org/sites/default/files/documents/Training Manual Update 8 12.pdf. Accessed June 14, 2013.

5. Lee DH, Buth KJ, Martin BJ, Yip AM, Hirsch GM. Frail patients are at increased risk for mortality and prolonged institutional care after cardiac surgery. Circulation. 2010;121:973-8.

6. Challa S, Sharkey JR, Chen M, Phillips CD. Association of resident, facility, and geographic characteristics with chronic undernutrition in a nationally represented sample of older residents in U.S. nursing homes. J Nutr Health Aging. 2007;11:179-84.

7. Beutler E, Waalen J. The definition of anemia: what is the lower limit of normal of the blood hemoglobin concentration? Blood. 2006;107:1747-50.

8. Watanabe A. Why albumin now? Let's think about albumin measurement methods, the definition of hypoalbuminemia, and microheterogeneity. Nutrition. 2005;21:1156-7.

9. Farhat JS, Velanovich V, Falvo AJ, Horst HM, Swartz A, Patton JH Jr, et al. Are the frail destined to fail? Frailty index as predictor of surgical morbidity and mortality in the elderly. J Trauma Acute Care Surg. 2012;72:1526-30; discussion 30-1.

10. Peng P, Hyder O, Firoozmand A, Kneuertz P, Schulick RD, Huang D, et al. Impact of sarcopenia on outcomes following resection of pancreatic adenocarcinoma. J Gastrointest Surg. 2012;16:1478-86.

11. Makary MA, Segev DL, Pronovost PJ, Syin D, Bandeen-Roche K, Patel P, et al. Frailty as a predictor of surgical outcomes in older patients. JAm Coll Surg. 2010; 210:901-8

12. Rockwood K, Stadnyk K, MacKnight C, McDowell I, Hebert R, Hogan DB. A brief clinical instrument to classify frailty in elderly people. Lancet. 1999;353: 205-6.

13. Sündermann S, Dademasch A, Praetorius J, Kempfert J, Dewey T, Falk V, et al. Comprehensive assessment of frailty for elderly high-risk patients undergoing cardiac surgery. Eur J Cardiothorac Surg. 2011;39:33-7.

14. Alexander KP, Newby LK, Cannon CP, Armstrong PW, Gibler WB, Rich MW, et al. Acute coronary care in the elderly, part I: non-ST-segment-elevation acute coronary syndromes: a scientific statement for healthcare professionals from the American Heart Association Council on Clinical Cardiology: in collaboration with the Society of Geriatric Cardiology. Circulation. 2007;115: 2549-69.

15. Rosamond W, Flegal K, Furie K, Go A, Greenlund K, Haase N, et al Heart disease and stroke statistics-2008 update: a report from the American Heart Association Statistics Committee and Stroke Statistics Subcommittee. Circulation. 2008;117:e25-146.

16. Brown JM, O'Brien SM, Wu C, Sikora JA, Griffith BP, Gammie JS Isolated aortic valve replacement in North America comprising 108,687 patients in 10 years: changes in risks, valve types, and outcomes in the Society of Thoracic Surgeons National Database. J Thorac Cardiovasc Surg. 2009;137: 82-90.

17. Roques F, Nashef SA, Michel P, Gauducheau E, de Vincentiis C, Baudet E, et al Risk factors and outcome in European cardiac surgery: analysis of the EuroSCORE multinational database of 19,030 patients. Eur J Cardiothorac Surg. 1999;15:816-22; discussion 22-3.

18. O'Brien SM, Shahian DM, Filardo G, Ferraris VA, Haan CK, Rich JB, et al. The Society of Thoracic Surgeons 2008 cardiac surgery risk models: part 2-isolated valve surgery. Ann Thorac Surg. 2009;88:S23-42.

19. Shahian DM, O'Brien SM, Filardo G, Ferraris VA, Haan CK, Rich JB, et al. The Society of Thoracic Surgeons 2008 cardiac surgery risk models: part 3 - valve plus coronary artery bypass grafting surgery. Ann Thorac Surg. 2009; 88:S43-62.

20. Ambler G, Omar RZ, Royston P, Kinsman R, Keogh BE, Taylor KM. Generic simple risk stratification model for heart valve surgery. Circulation. 2005;112: 224-31.

21. Vahanian A, Iung B, Himbert D, Depoix JP, Nataf P. Understanding risk assessment in cardiac surgery patients. Semin Thorac Cardiovasc Surg. 2010 22:285-90.

22. Woodhouse KW, Wynne H, Baillie S, James OF, Rawlins MD. Who are the frai elderly? Q J Med. 1988;68:505-6.

23. Rockwood K, Fox RA, Stolee P, Robertson D, Beattie BL. Frailty in elderly people: an evolving concept. Can Med Assoc J. 1994;150:489-95.

24. Robinson TN, Wallace JI, Wu DS, Wiktor A, Pointer LF, Pfister SM, et al. Accumulated frailty characteristics predict postoperative discharge institutionalization in the geriatric patient. J Am Coll Surg. 2011;213:37-42; discussion 42-4.

25. Chin APMJ, Dekker JM, Feskens EJ, Schouten EG, Kromhout D. How to select a frail elderly population? A comparison of three working definitions J Clin Epidemiol. 1999;52:1015-37.

26. Fried LP, Tangen CM, Walston J, Newman AB, Hirsch C, Gottdiener J, et al Frailty in older adults: evidence for a phenotype. J Gerontol A Biol Sci Med Sci. 2001;56:M146-56.

27. Rockwood K, Song X, MacKnight C, Bergman H, Hogan DB, McDowell I, et al A global clinical measure of fitness and frailty in elderly people. Can Med Assoc J. 2005; 173:489-95.

28. Mack M. Frailty and aortic valve disease. J Thorac Cardiovasc Surg. 2013;145: S7-10.

29. Schoenenberger AW, Stortecky S, Neumann S, Moser A, Juni P, Carrel T, et al Predictors of functional decline in elderly patients undergoing transcatheter aortic valve implantation (TAVI). Eur Heart J. 2013;34:684-92.

30. Stortecky S, Schoenenberger AW, Moser A, Kalesan B, Juni P, Carrel T, et al Evaluation of multidimensional geriatric assessment as a predictor of mortality and cardiovascular events after transcatheter aortic valve implantation. JACC Cardiovasc Interv. 2012;5:489-96.

31. de Arenaza DP, Pepper J, Lees B, Rubinstein F, Nugara F, Roughton M, et al Preoperative 6-minute walk test adds prognostic information to EuroSCORE in patients undergoing aortic valve replacement. Heart. 2010;96:113-7.

32. Peng PD, van Vledder MG, Tsai S, de Jong MC, Makary M, Ng J, et al Sarcopenia negatively impacts short-term outcomes in patients undergoing hepatic resection for colorectal liver metastasis. HPB (Oxford). 2011;13: 439-46.

33. Lee JS, He K, Harbaugh CM, Schaubel DE, Sonnenday CJ, Wang SC, et al Frailty, core muscle size, and mortality in patients undergoing open abdominal aortic aneurysm repair. J Vasc Surg. 2011;53:912-7.

34. Shah AA, Craig DM, Andersen ND, Williams JB, Bhattacharya SD, Shah SH, et al. Risk factors for 1-year mortality after thoracic endovascular aortic repair. J Thorac Cardiovasc Surg. 2013;145:1242-7.

35. Santos-Eggimann B, Cuenoud P, Spagnoli J, Junod J. Prevalence of frailty in middle-aged and older community-dwelling Europeans living in 10 countries. J Gerontol A Biol Sci Med Sci. 2009;64:675-81. 


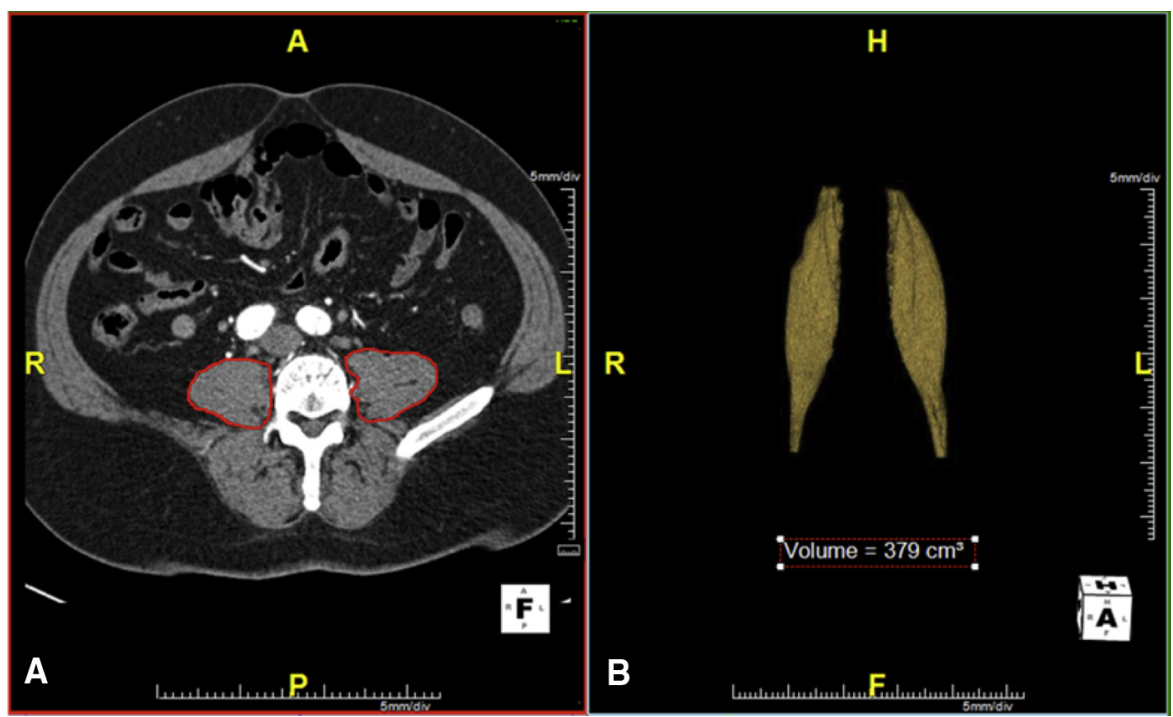

FIGURE E1. Representation of total psoas volume (TPV) measurement. A, Axial image of abdomen at L4 level, with red line outlining psoas muscles bilaterally. B, Three-dimensional image of bilateral psoas muscles, including calculation of TPV, after reconstruction on 3-dimensional workstation.

TABLE E1. Frailty indicators

\begin{tabular}{lcc}
\hline \multicolumn{1}{c}{ Component } & Frail $(\mathbf{n}=\mathbf{1 4 8})$ & Not frail $(\mathbf{n}=\mathbf{4 2 6})$ \\
\hline Age $>70 \mathrm{y}$ & $66(44.6)$ & $26(6.1)$ \\
BMI $<18.5 \mathrm{~kg} / \mathrm{m}^{2}$ & $7(4.7)$ & $5(1.1)$ \\
History of stroke & $25(16.9)$ & $15(3.5)$ \\
TPV in lower quartile & $46(31.1)$ & $20(4.7)$ \\
Anemia & $112(75.7)$ & $60(14.1)$ \\
Hypoalbuminemia & $104(70.3)$ & $20(4.7)$ \\
\hline
\end{tabular}

Data presented as $\mathrm{n}(\%)$. Anemia defined as $<12.0 \mathrm{~g} / \mathrm{dL}$ for women or $<13.0 \mathrm{~g} / \mathrm{dL}$ for men. Hypoalbuminemia defined as $<3.5 \mathrm{~g} / \mathrm{dL}$. BMI, Body mass index; $T P V$, total psoas volume.
TABLE E2. Frailty scores

\begin{tabular}{lcc}
\hline Frailty score & Frail $(\mathbf{n}=\mathbf{1 4 8})$ & Not frail $(\mathbf{n}=\mathbf{4 2 6})$ \\
\hline 0 & NA & $280(65.7)$ \\
1 & NA & $146(34.3)$ \\
2 & $93(62.8)$ & NA \\
3 & $47(31.8)$ & NA \\
4 & $7(4.7)$ & NA \\
5 & $1(0.7)$ & NA \\
6 & $0(0)$ & NA \\
\hline
\end{tabular}

Data presented as $\mathrm{n}(\%) . N A$, Not applicable. 